\title{
Supplement for \\ Critical impacts of global warming on land ecosystems
}

\author{
S. Ostberg ${ }^{1}$, W. Lucht ${ }^{1,2}$, S. Schaphoff ${ }^{1}$, and D. Gerten ${ }^{1}$ \\ ${ }^{1}$ Potsdam Institute for Climate Impact Research, Research Domain 1: Earth System Analysis, Telegraphenberg A62, 14473 \\ Potsdam, Germany \\ ${ }^{2}$ Dept. of Geography, Humboldt-Universität zu Berlin, Berlin, Germany
}

\section{Model settings and simulation protocol}

All vegetation simulations are computed on a 0.5 by $0.5^{\circ}$ spatial grid using monthly climate data to force LPJmL. Since the focus of this study is on natural vegetation, the modules for agriculture, represented by 12 crop-functional types (CFTs) (Bondeau et al., 2007), and biomass plantations, represented by three types of biomass production for bioenergy (Beringer et al., 2011), are switched off. Potential natural vegetation is simulated, represented by the nine plantfunctional types (PFT) listed in Table S1. The fire module has been modified to include fire carbon fluxes for the grass PFTs which in the standard version of the model are limited to tree PFTs. Fire resistance of grass is set to 0.5 meaning that leaf biomass may be reduced by up to $50 \%$ in a given year if conditions for fire (soil moisture and litter availability) are met. The change is made primarily to avoid infinite relative increases in fire carbon emissions in grasslands that are projected to experience woody encroachment in the future.

The model is spun-up for 10020 years using preindustrial atmospheric $\mathrm{CO}_{2}$ concentrations (280 ppmv) and cycling the first 30 years of the historical climatological data (CRU/GPCC, see Climate uncertainty section in main text) repeatedly to allow vegetation structure and carbon pools to reach equilibrium. The spin-up is followed by a transient run from 1901 to the end of 2009 using the full CRU/GPCC climate time-series and observed atmospheric $\mathrm{CO}_{2}$ concentrations. The last 30 years of the historical run (1980-2009) provide the reference state from which ecosystems diverge under projected climate change. All 152 climate scenario runs are started from the same reference state and forced by the climate scenario data, running from 2010 to 2115 . A specific atmospheric $\mathrm{CO}_{2}$ concentration trajectory, provided by the MAGICC6 model, is used for each of the 8 GMT trajec-
Table S1. Plant-functional types in LPJmL

\begin{tabular}{ll}
\hline Name & Abbreviation \\
\hline Tropical broadleaved evergreen tree & TrBE \\
Tropical broadleaved raingreen tree & TrBR \\
Temperate needleleaved evergreen tree & TeNE \\
Temperate broadleaved evergreen tree & TeBE \\
Temperate broadleaved summergreen tree & TeBS \\
Boreal needleleaved evergreen tree & $\mathrm{BoNE}$ \\
Boreal summergreen tree (primarily & $\mathrm{BoS}$ \\
broadleaved, but including larch) & \\
C3 grass & $\mathrm{C} 3$ \\
C4 grass & $\mathrm{C} 4$ \\
\hline
\end{tabular}

tories. The last 30 years of the scenario period provide the future state that is compared to the reference state.

Vegetation simulations cover a total of 133 million $\mathrm{km}^{2}$ or about $90 \%$ of the Earth's land surface, excluding areas permanently covered in ice like Antarctica and most of Greenland. About 41.7 million $\mathrm{km}^{2}$ or $31 \%$ of the simulated area are classified as agricultural areas (cropland, pasture and managed grassland, Fig. S1) and not considered in the analysis. Agricultural areas are based on MIRCA2000 (Portmann et al., 2010), as modified by Fader et al. (2010). This leaves a total base area of 91.6 million $\mathrm{km}^{2}$. Almost $86 \%$ of this base area is covered with natural to semi-natural vegetation during the reference period, while the rest is classified as non-vegetated (primarily desert and some tundra regions in Fig. S3).

The $\Gamma$ metric is computed for each grid cell for all 152 scenario runs based on the model parameters in Table 1 in the main text. In summing up affected areas across grid cells 
each grid cell area is reduced by its agricultural area fraction. Global mean values of the model parameters, used to compute the global importance component in $\Gamma$, are derived as area-weighted means, using only the non-agricultural area of each cell. Since our study investigates climate change effects, not land-use change effects, land-use patterns are kept constant in the future assuming no further anthropogenic conversion of natural ecosystems.

\section{Vegetation-structural changes}

Changes in vegetation structure $\Delta V$ are one component of the change metric $\Gamma$. To compare vegetation structure between a future ecosystem state and present-day conditions we use a modified version of the $\Delta V$ metric developed by Sykes et al. (1999), adapted to the PFTs simulated by LPJmL (Tab. S1). The metric measures the difference in vegetation structure in terms of the importance of broad life form types (grass, trees, bare ground), further characterised by their assigned attributes.

$\Delta V(i, j)=1-\sum_{k}\left\{\min \left(V_{i k}, V_{j k}\right) *\left[1-\sum_{l}\left(\omega_{k l} *\left|a_{i k l}-a_{j k l}\right|\right)\right]\right\}$

$V_{i k}$ and $V_{j k}$ describe the area fractions covered by life form $k$ in ecosystem $i$ and $j, a_{i k l}$ and $a_{j k l}$ are the attributes $l$ of lifeform $k$ in ecosystem $i$ and $j$, respectively. Attributes are weighted for each life form by $\omega_{k l}$. Attributes can be climatic (tropical, temperate, boreal), or phenologic (evergreen, deciduous) or describe leaf types (needleleaved, broadleaved).

Table S2 lists modelled PFTs categorised into life forms tree and grass, together with their assigned attributes. The remaining area fraction not covered by any PFT is considered bare ground, without any further attributes. 


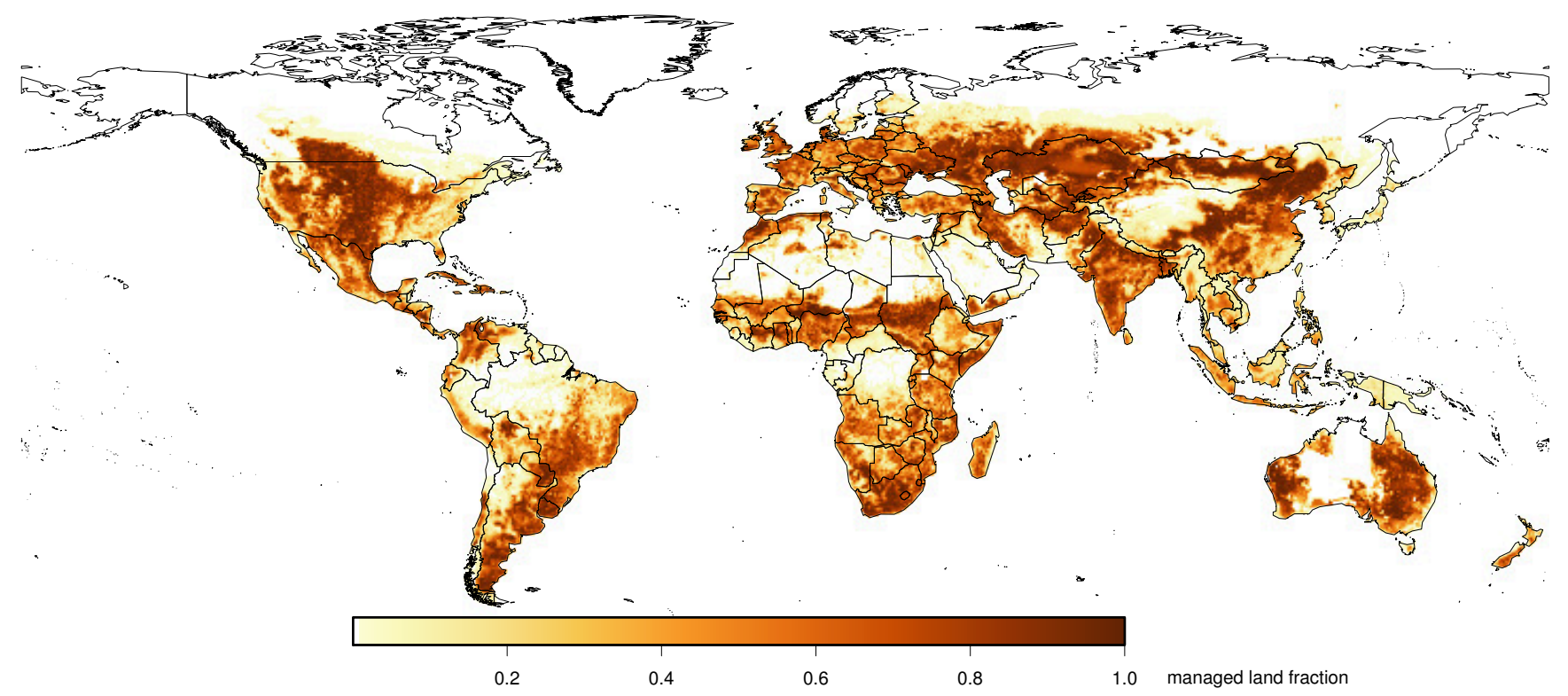

Fig. S1. Fraction of each grid cell used as crop land or managed grassland.

Table S2. Plant-functional types with their assigned attributes. For PFT abbreviations see Table S1

\begin{tabular}{lllll}
\hline Lifeform & Attributes & & & \\
\hline Tree: & Evergreenness & Needleleavedness & Tropicalness & Borealness \\
TrBE & 1 & 0 & 1 & 0 \\
TrBR & 0 & 0 & 1 & 0 \\
TeNE & 1 & 1 & 0 & 0 \\
TeBE & 1 & 0 & 0 & 0 \\
TeBS & 0 & 0 & 0 & 0 \\
BoNE & 1 & 1 & 0 & 1 \\
BoS & 0 & $0.25^{*}$ & 0 & 1 \\
(attribute weights: & 0.2 & 0.2 & 0.3 & $0.3)$ \\
\hline
\end{tabular}

\begin{tabular}{ll}
\hline Grass: & Tropicalness \\
C3 grass & 0 \\
C4 grass & 1 \\
(attribute weights: & 0.3 ) \\
\hline${ }^{*}$ BoS primarily represents broadleaved trees, but includes larchs.
\end{tabular}




\section{Illustrative examples of the change metric}

We compute $\Gamma$ values for hypothetical transformations between present-day biomes, using the biome classification below. To compare biomes, all LPJmL outputs used to compute the metric (Tab. 1 in main text) are averaged over all grid cells of each biome. Biome means of all parameters are then used to describe two different biomes as hypothetical states of the same biome. Interannual variability during the reference period (required for the change to variability ratio $S$ in Equation 1 in the main text) is computed for each grid cell and then averaged over all biome cells instead of estimating it from averaged LPJ outputs. The table in Fig. S2 is not symmetric because for the local change component $c$ and ecosystem balance $b$ changes are normalised to the reference state (which is different depending on whether biome $i$ shifts into biome $j$ or biome $j$ shifts into biome $i$ ). In addition, $c, g$ and $b$ are scaled by a factor $S$ representing the natural state variability of the original biome. $S\left(g, \sigma_{g}\right)$ may differ even though $g$ is identical. The correct reading direction for Fig. S2 is that biomes listed on the horizontal axis shift into biomes listed on the vertical axis. For quick visual reference, the table background is shaded based on $\Gamma$ values (from white, $\Gamma=0$, to black, $\Gamma=1$ ).

Table S3 uses the example of a change between the two tropical forest biomes and between a boreal forest and a tundra to illuminate why $\Gamma$ depends on the direction of change.

\subsection{Biome classification scheme}

The biome classification used in this study is based primarily on the composition of PFTs modelled in LPJmL, except for the tundra biome which is based on a temperature limit. The classification uses a sequence of simple rules such as total vegetation cover to delineate deserts, and increasing tree cover to differentiate between grasslands, savannas, woody savannas and forests. Forests are categorised further based on the dominant tree PFT. For tropical forests, the classification includes an additional biomass limit. Figure S3a shows a map of present-day biomes derived from LPJmL output for the reference period 1980-2009. Figure S4 illustrates the classification rules. 




Fig. S2. Illustrative $\Gamma$ values for a complete transformation between present-day biomes

Table S3. Example of $\Gamma$ components in biome transformation. For defintions of the components see main text.

\begin{tabular}{l|cccccccc}
\hline Biome transformation & $\Gamma$ & $\Delta \mathbf{V}$ & $c$ & $S\left(c, \sigma_{c}\right)$ & $g$ & $S\left(g, \sigma_{g}\right)$ & $b$ & $S\left(b, \sigma_{b}\right)$ \\
\hline Tropical Rainforest $\Rightarrow$ Tropical Seasonal \& Deciduous Forest & 0.31 & 0.04 & 0.31 & 1 & 0.72 & 1 & 0.16 & 0.97 \\
Tropical Seasonal \& Deciduous Forest $\Rightarrow$ Tropical Rainforest & 0.46 & 0.04 & 0.93 & 1 & 0.72 & 0.86 & 0.25 & 1 \\
Arctic Tundra $\Rightarrow$ Boreal Deciduous Forest & 0.73 & 0.81 & 1 & 1 & 0.34 & 1 & 0.80 & 1 \\
Boreal Deciduous Forest $\Rightarrow$ Arctic Tundra & 0.45 & 0.81 & 0.45 & 1 & 0.34 & 1 & 0.20 & 0.98 \\
\hline
\end{tabular}




\section{a) LPJmL-derived biomes}

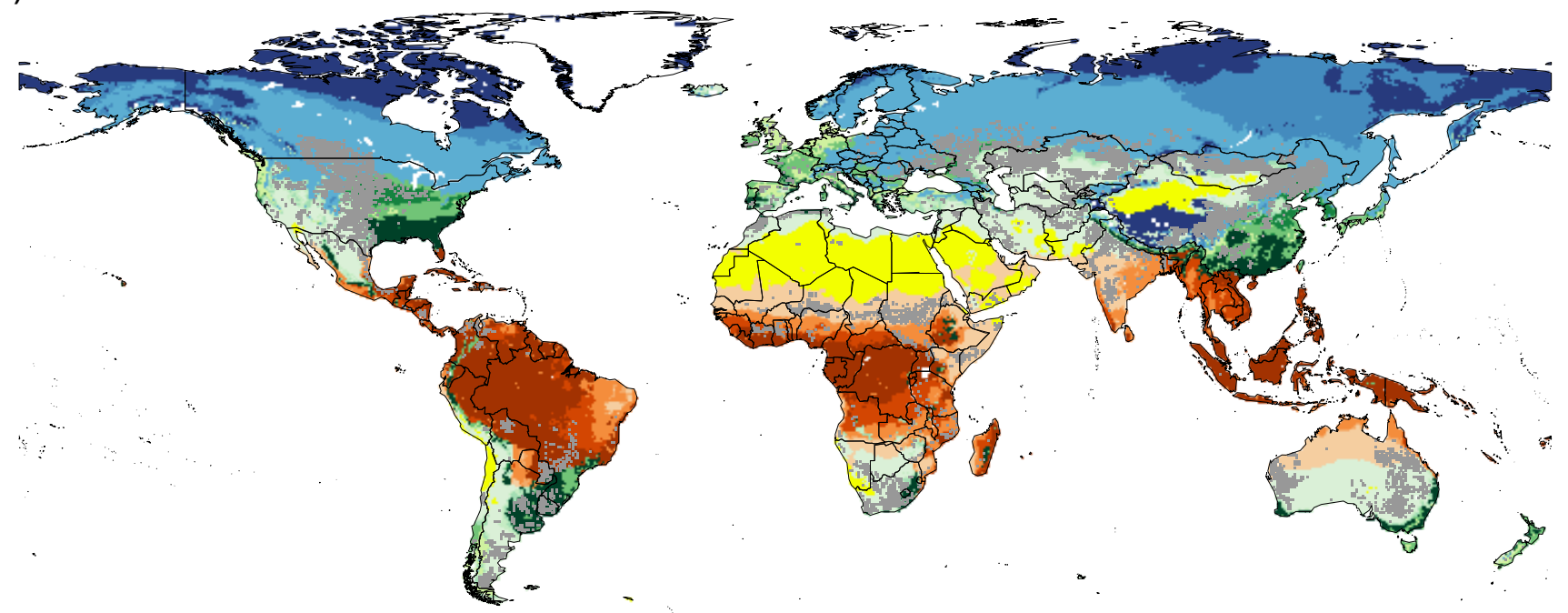

b) MODIS-derived biomes

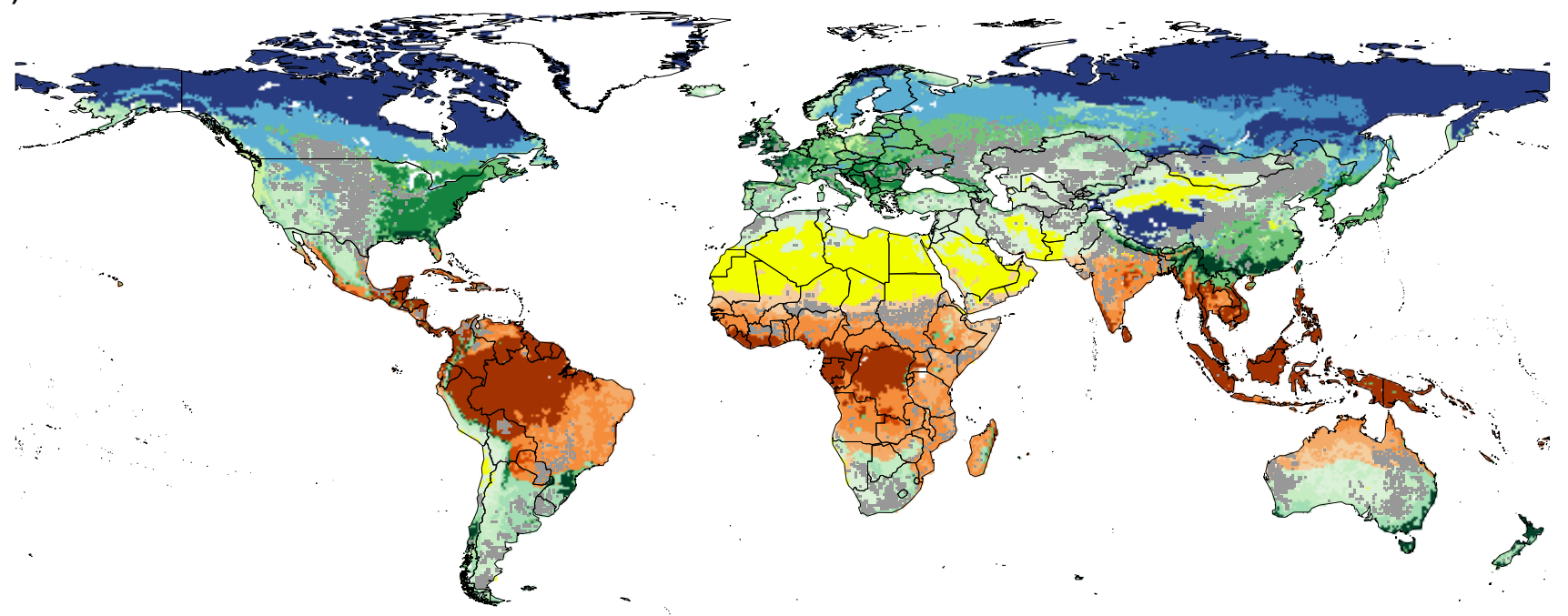

Tropical Rainforest

Tropical Seasonal \& Deciduous Forest

$\square$ Warm Woody Savanna, Woodland \& Shrubland

$\square$ Warm Savanna \& Open Shrubland

$\square$ Warm Grassland

Desert
Temperate Broadleaved Evergreen Forest

$\square$ Temperate Broadleaved Deciduous Forest

$\square$ Mixed Forest

$\square$ Temperate Coniferous Forest

$\square$ Temperate Woody Savanna, Woodland \& Shrubland

$\square$ Temperate Savanna \& Open Shrubland

$\square$ Temperate Grassland
Boreal Evergreen Forest

$\square$ Boreal Deciduous Forest

$\square$ Arctic Tundra

$\square$ Rocks and Ice

Human-dominated

Fig. S3. Present-day biome classification derived from a) LPJmL results and b) MODIS land cover data. Grid cells with more than $80 \%$ cropland and pasture are marked as human-dominated. 


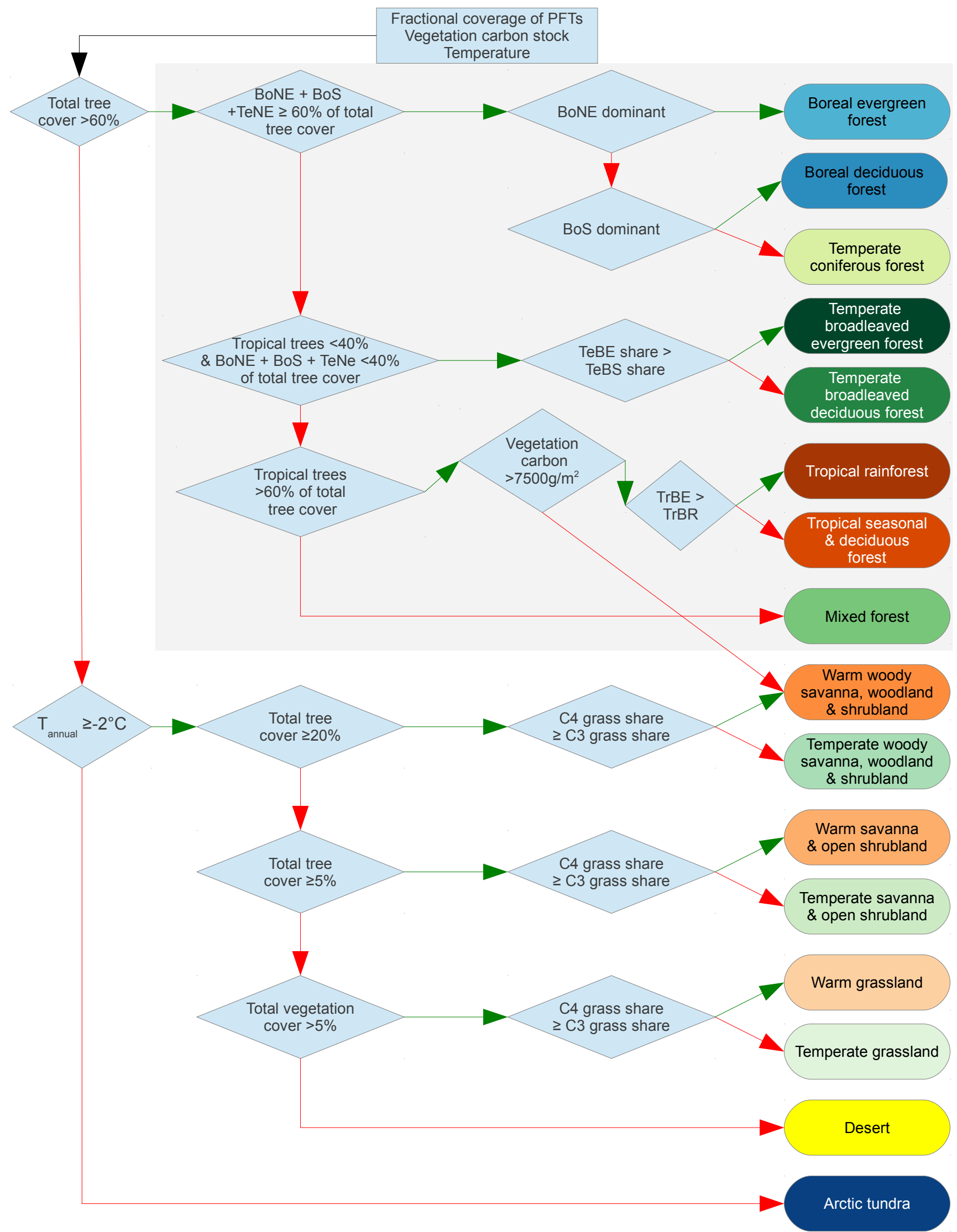

Fig. S4. Biome classification scheme. Each rhombus represents a classification rule. Classification starts in the upper left corner and proceeds through the rule chain based on whether a rule is fulfilled (green arrow) or not (red arrow). For PFT abbreviations see table S1 


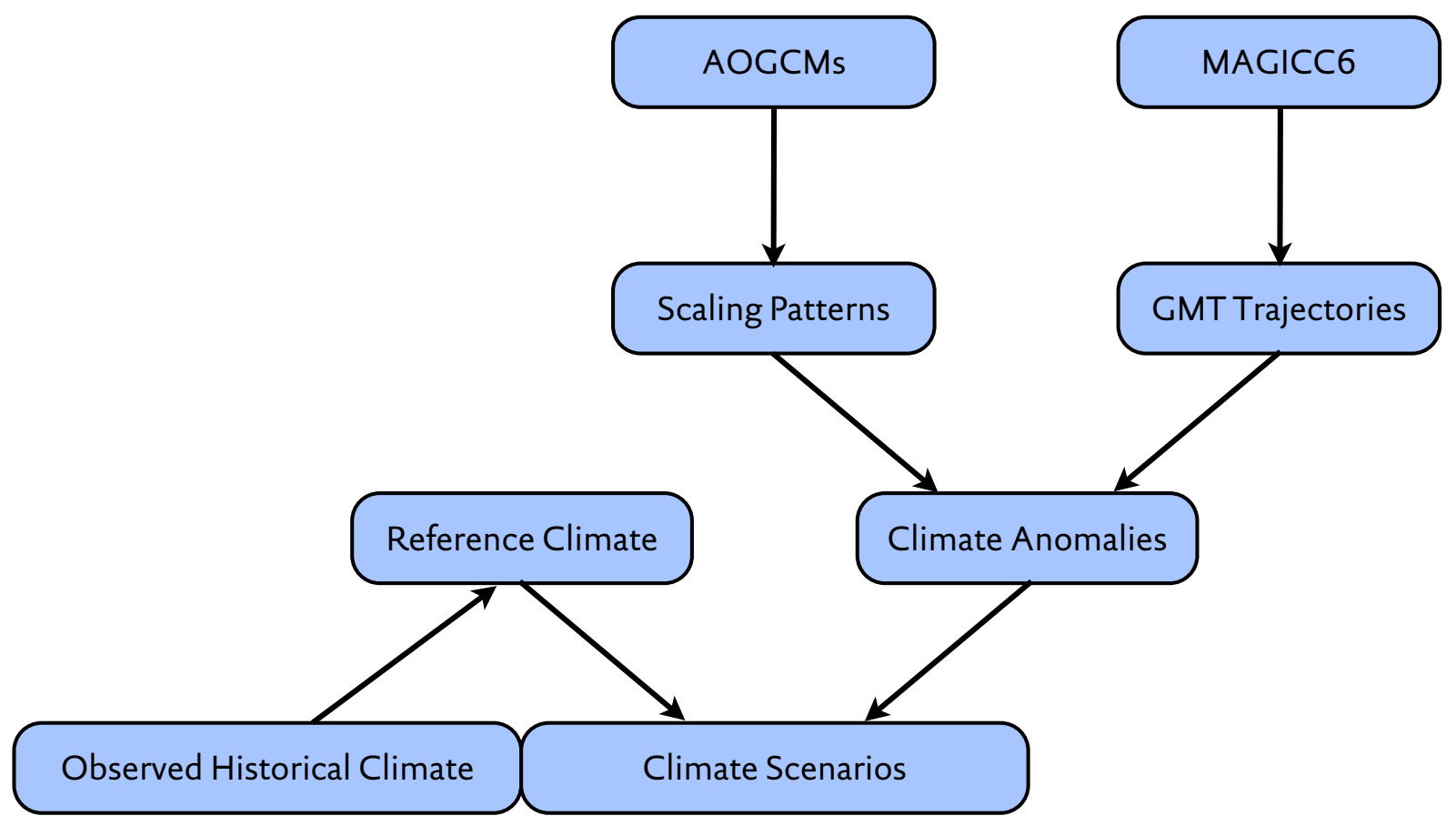

Fig. S5. Flow chart of data processing for the generation of the "PanClim" climate scenarios. Source: Heinke et al. (in press) 


\section{Discussion of modelled vegetation dynamics}

The biome distribution in Fig. S3a is a result of bioclimatic limits and modelled vegetation dynamics as PFTs in LPJmL compete for space and resources. While the processes controlling competition among PFTs are difficult to validate, it is possible to compare the resulting vegetation composition to observations. We use MODIS land cover data and apply the biome classification scheme described above. The Land Cover Type Yearly Climate Modelling Grid Version 5 (short name: MCD12C1) ${ }^{1}$ distinguishes 17 land cover classes defined by the International Geosphere Biosphere Programme (IGBP), which includes 11 natural vegetation classes, 3 developed and mosaicked land classes, and 3 non-vegetated land classes (Table S4). In order to compare actual land cover as derived from MODIS satellite imagery with potential natural vegetation as simulated by LPJmL, some modifications are necessary to remove human land use from the MODIS data. Since there is no distinction between natural and anthropogenic grasslands, MODIS grassland fractions are reduced by the managed grassland fraction used to mask grid cell areas in LPJmL (see Model settings and simulation protocol above). In addition, the 3 developed and mosaicked land classes as well as the water and the snow and ice class are discarded and fractional cover of the remaining classes is scaled up accordingly. Bioclimatic limits as implemented in LPJmL are used to map MODIS forest classes to LPJmL tree PFTs and to distinguish between $\mathrm{C} 3$ and $\mathrm{C} 4$ grass. Without further information on tree composition in the MODIS mixed forest, shrubland and savanna classes, tree cover from these classes is distributed equally to the 2 dominant tree PFTs.

Overall, there is good agreement between the biomes derived from LPJmL and MODIS (Fig. S3). LPJmL simulates more forest and less savanna in tropical Africa and South America. There is continuing debate on the mechanisms controlling the persistence of grass-tree mixtures in savannas, including resource competition, fire, herbivory and rainfall variability (Sankaran et al., 2004). Some of these processes, such as herbivory, cannot be reproduced in the model. Others like rainfall variability depend heavily on the quality of the climate data used, with limited availability of station data especially in central Africa possibly affecting accuracy (Rudolf et al., 2010). On the other hand, the discrepancies between MODIS and LPJmL are mostly found in regions with considerable human land use (compare Fig. S1), where there is also greater uncertainty regarding the MODIS-derived biome class.

The transition zone between boreal forest and tundra is another region of disagreement between MODIS and LPJmL. Boreal trees extend farther north in LPJmL because the model version used in this study does not include permafrost.

\footnotetext{
${ }^{1}$ NASA Land Processes Distributed Active Archive Center (LP DAAC). MODIS MCD12C1. USGS/Earth Resources Observation and Science (EROS) Center, Sioux Falls, South Dakota. 2008.
}

A new development version including permafrost dynamics shows better results for this region.

There are also differences regarding the dominant tree types in some forests. MODIS data suggest a higher fractional coverage of temperate broadleaved deciduous trees than simulated by LPJmL. It is unclear how much of this disagreement is an artefact of the re-classification algorithm.

\section{Projected risk of ecosystem changes across biomes}

In addition to the globally affected areas from Fig. 1 in the main text, Figure S6 presents results differentiated by biomes. Areas are classified based on present-day vegetation (Fig. S3a). Areas of ecosystems projected to shift to a different biome type under climate change are still grouped according to their present-day biome classes.

For the sake of readability, Fig. 3 in the main text uses a reduced number of biome classes. The biomes "Warm Woody Savanna, Woodland \& Shrubland" and "Warm Savanna \& Open Shrubland" are grouped as "Warm Savanna \& Shrubland", "Temperate Woody Savanna, Woodland \& Shrubland" and "Temperate Savanna \& Open Shrubland" are grouped as "Temperate Savanna \& Shrubland", and "Temperate Broadleaved Deciduous Forest" and "Mixed Forest" are grouped as "Temperate Summergreen \& Mixed Forest".

Figure $\mathrm{S} 7$ shows the dimensions of change for all 16 biome classes. It is the full version of Fig. 4 in the main text. 
Table S4. MODIS land cover classes. To derive biomes, classes are redistributed as percentage tree and grass cover and mapped to LPJmL PFTs. For PFT abbreviations see Table S1

\begin{tabular}{|c|c|c|c|}
\hline MODIS class & $\begin{array}{l}\text { Re-map } \\
\% \text { tree }\end{array}$ & $\begin{array}{l}\text { ed to } \\
\% \text { grass }\end{array}$ & PFTs \\
\hline Water & 0 & 0 & discarded \\
\hline Evergreen Needleleaf Forest & 95 & 5 & trees: TeNE, BoNE, grass: C3, C4 \\
\hline Evergreen Broadleaf Forest & 95 & 5 & trees: TrBE, TeBE, grass: C3, C4 \\
\hline Deciduous Needleleaf Forest & 95 & 5 & trees: $\mathrm{BoS}, \mathrm{TrBR}^{(1)}, \mathrm{TeNE}^{(1)}$, grass: $\mathrm{C} 3, \mathrm{C} 4$ \\
\hline Deciduous Broadleaf Forest & 95 & 5 & trees: TrBR, TeBS, grass: C3, C4 \\
\hline Mixed Forests & 95 & 5 & trees: dominant tree PFTs, grass: C3, C4 \\
\hline Closed Shrublands & 80 & 20 & trees: dominant tree PFTs, grass: $\mathrm{C} 3, \mathrm{C} 4$ \\
\hline Open Shrublands & 5 & 95 & trees: dominant tree PFTs, grass: $\mathrm{C} 3, \mathrm{C} 4$ \\
\hline Woody Savannas & 50 & 50 & trees: dominant tree PFTs, grass: $\mathrm{C} 3, \mathrm{C} 4$ \\
\hline Savannas & 10 & 90 & trees: dominant tree PFTs, grass: $\mathrm{C} 3, \mathrm{C} 4$ \\
\hline Grasslands $^{(2)}$ & 0 & 100 & $\mathrm{C} 3, \mathrm{C} 4$ \\
\hline Permanent Wetlands & 0 & 100 & $\mathrm{C} 3, \mathrm{C} 4$ \\
\hline Croplands & 0 & 0 & discarded \\
\hline Urban and Built-Up & 0 & 0 & discarded \\
\hline Cropland/Natural Vegetation Mosaic & 20 & 0 & discarded \\
\hline Snow and Ice & 0 & 0 & discarded \\
\hline Barren or Sparsely Vegetated & 0 & 2.5 & $\mathrm{C} 3, \mathrm{C} 4$ \\
\hline
\end{tabular}

(1) There are no direct equivalents of deciduous needleleaved PFTs for tropical and temperate climates, so the closest match is used.

${ }^{(2)}$ MODIS grassland fraction reduced by managed grassland fraction 

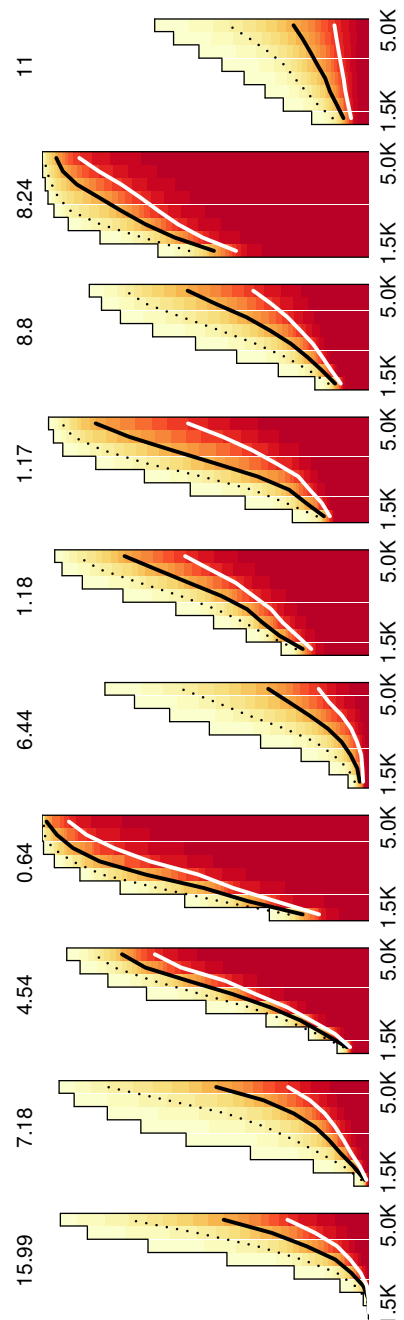

$\stackrel{\hat{N}}{\stackrel{2}{-}}$

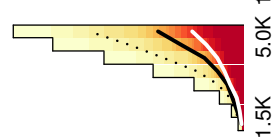

ํำ
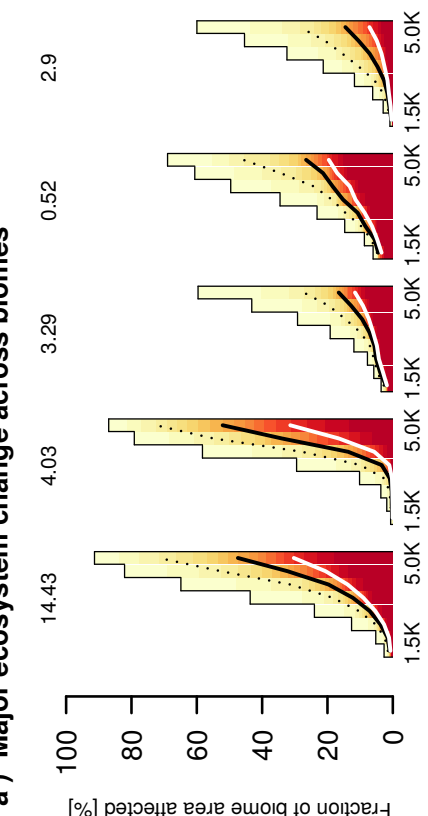
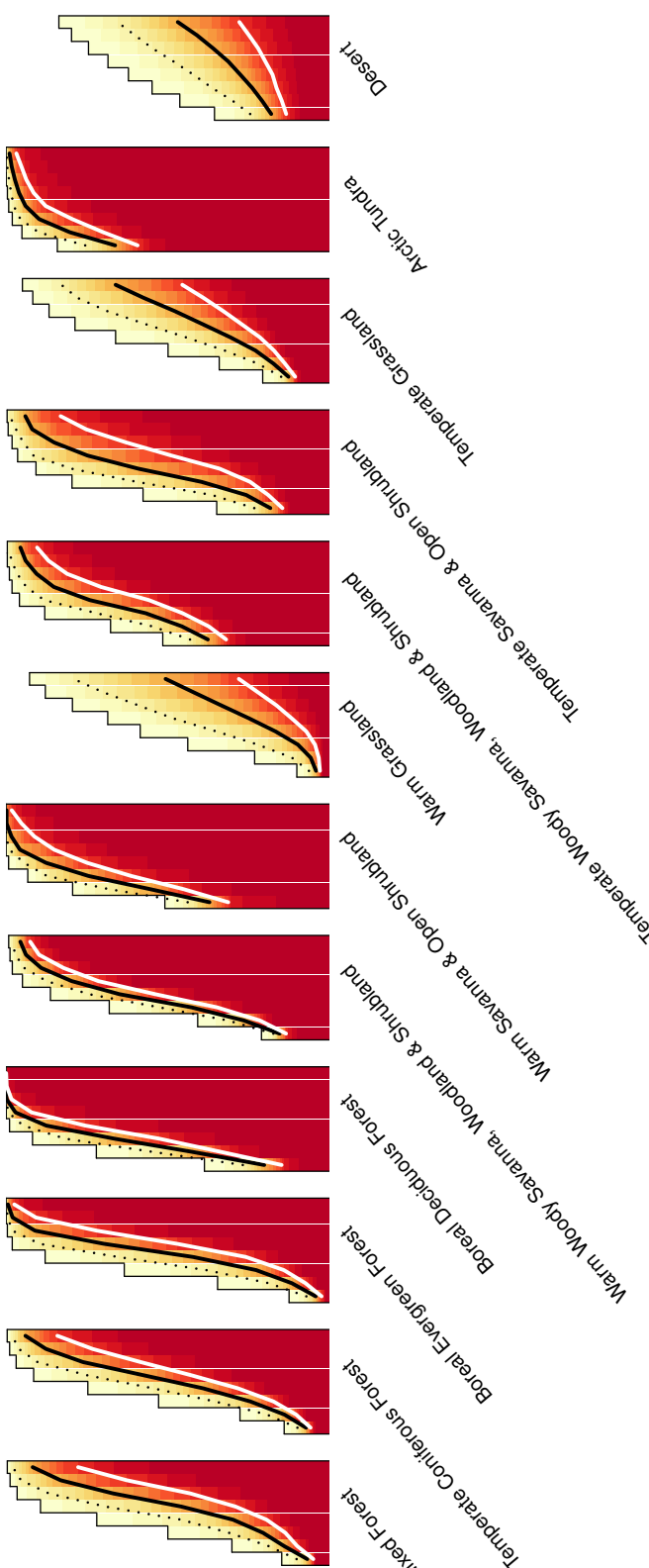

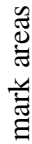

$\stackrel{\mathscr{0}}{\Xi}$

$\frac{4}{\tilde{g}}$

몽

o

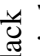

s.

है

궁

क

蒫 

2 degree target
current emissions
reduction pledges
business-as-usual
emissions growth
(5 K warming)
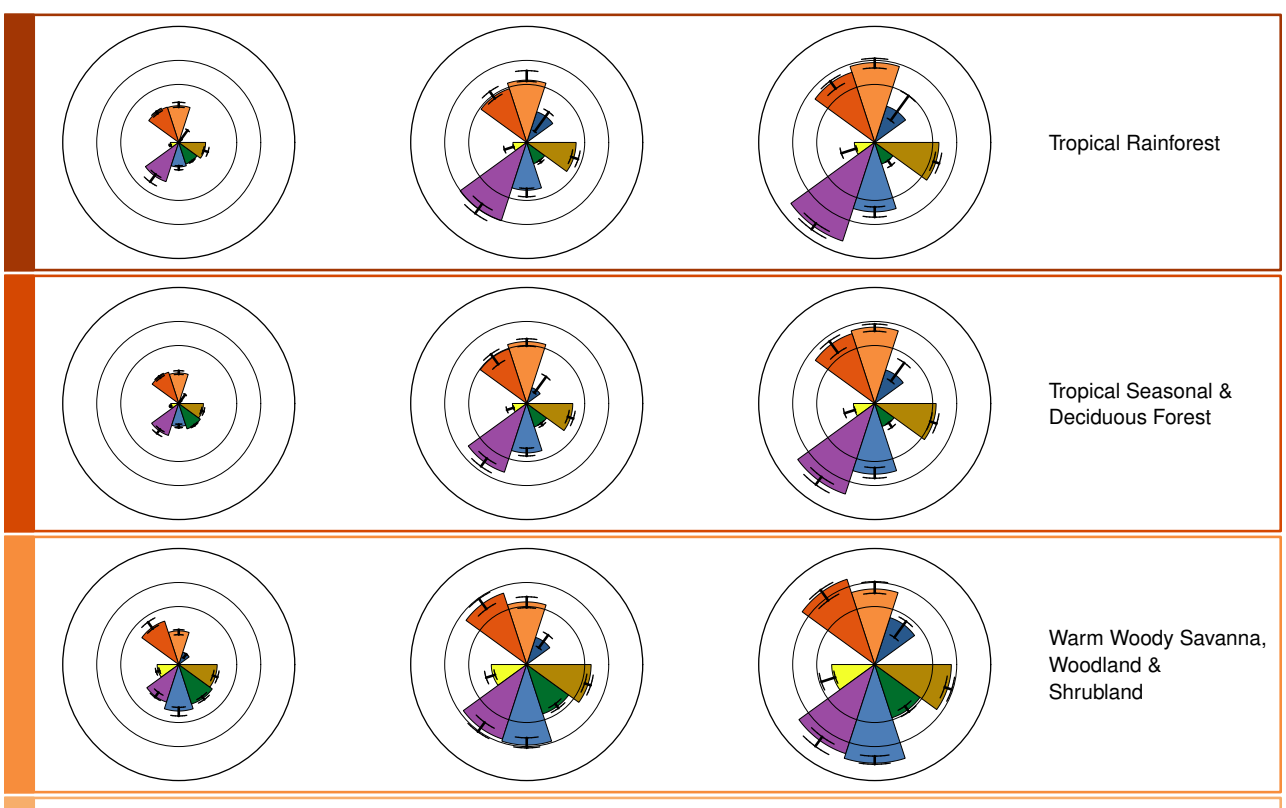

Warm Woody Savanna,

Woodland \&

Shrubland
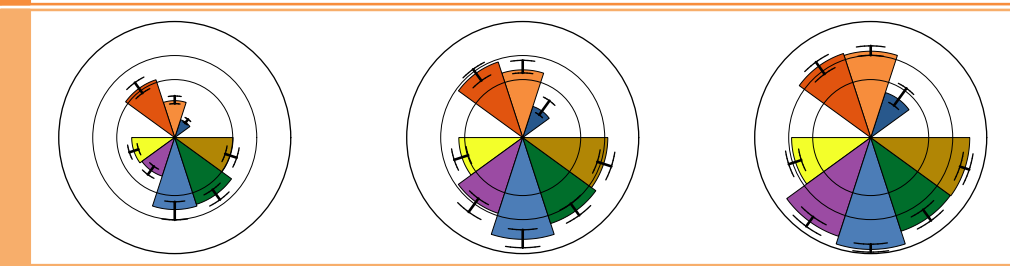

Warm Savanna \& Open Shrubland
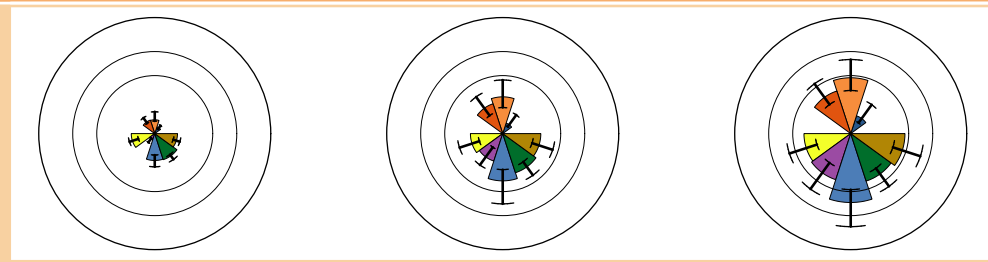

Warm Grassland
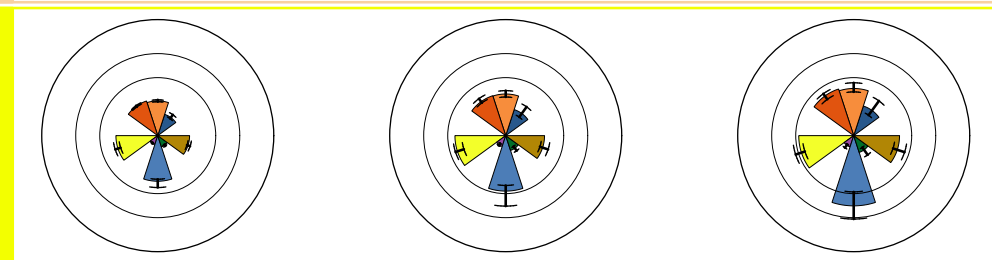

Desert
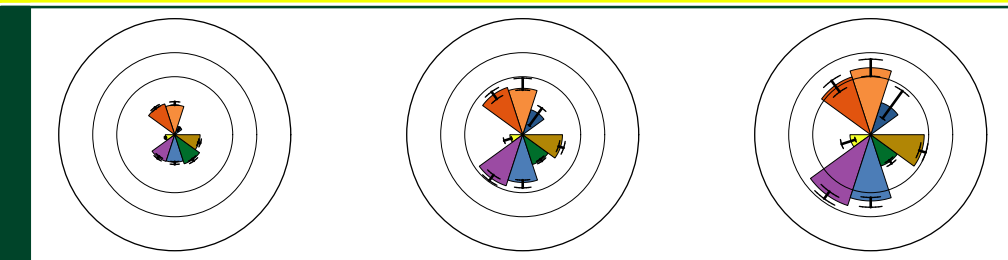

Temperate

Broadleaved

Evergreen Forest
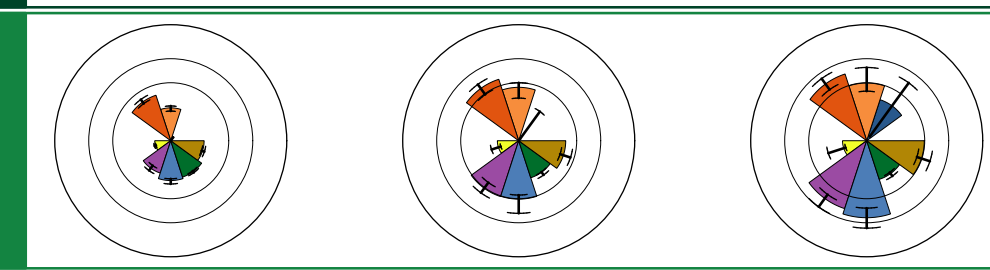

Temperate

Broadleaved

Deciduous Forest
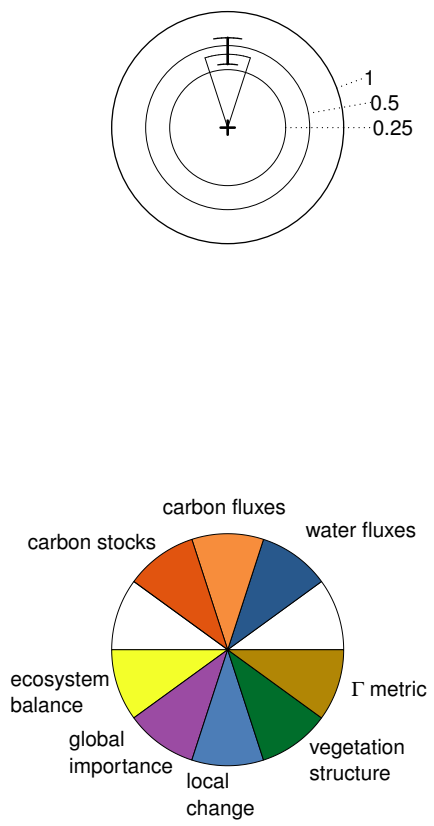

Fig. S7. Dimensions of ecosystem change for biomes. For definitions of the variables see Fig. 4 in the main text. Biome colours correspond to maps in Fig. S3 


$\begin{array}{ccc}2 \text { degree target } & \begin{array}{c}\text { current emissions } \\ \text { reduction pledges }\end{array} & \text { business-as-usual } \\ & (3.5 \mathrm{~K} \text { warming }) & \text { emissions growth }\end{array}$
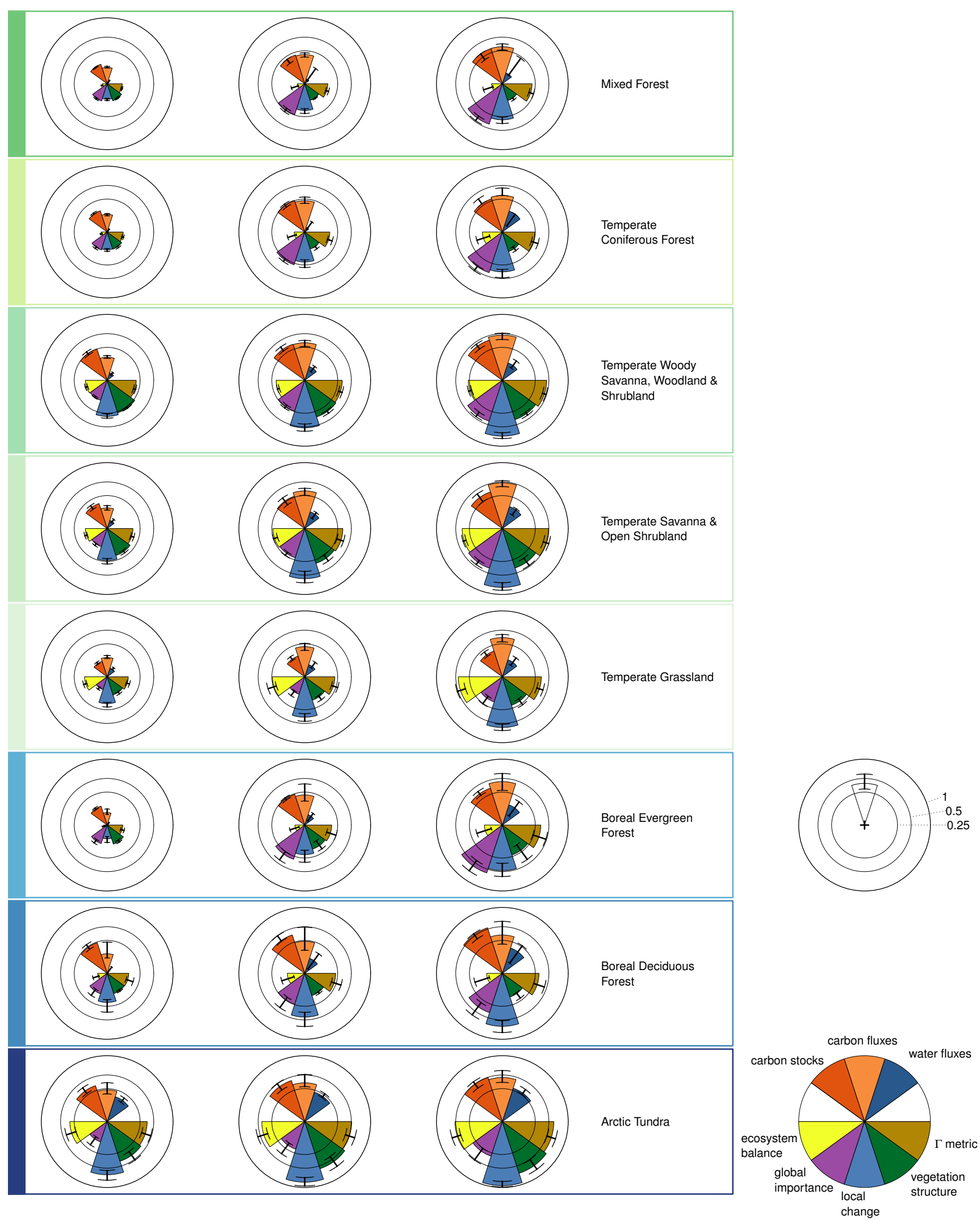

Fig. S7. Dimensions of ecosystem change for biomes (continued). 


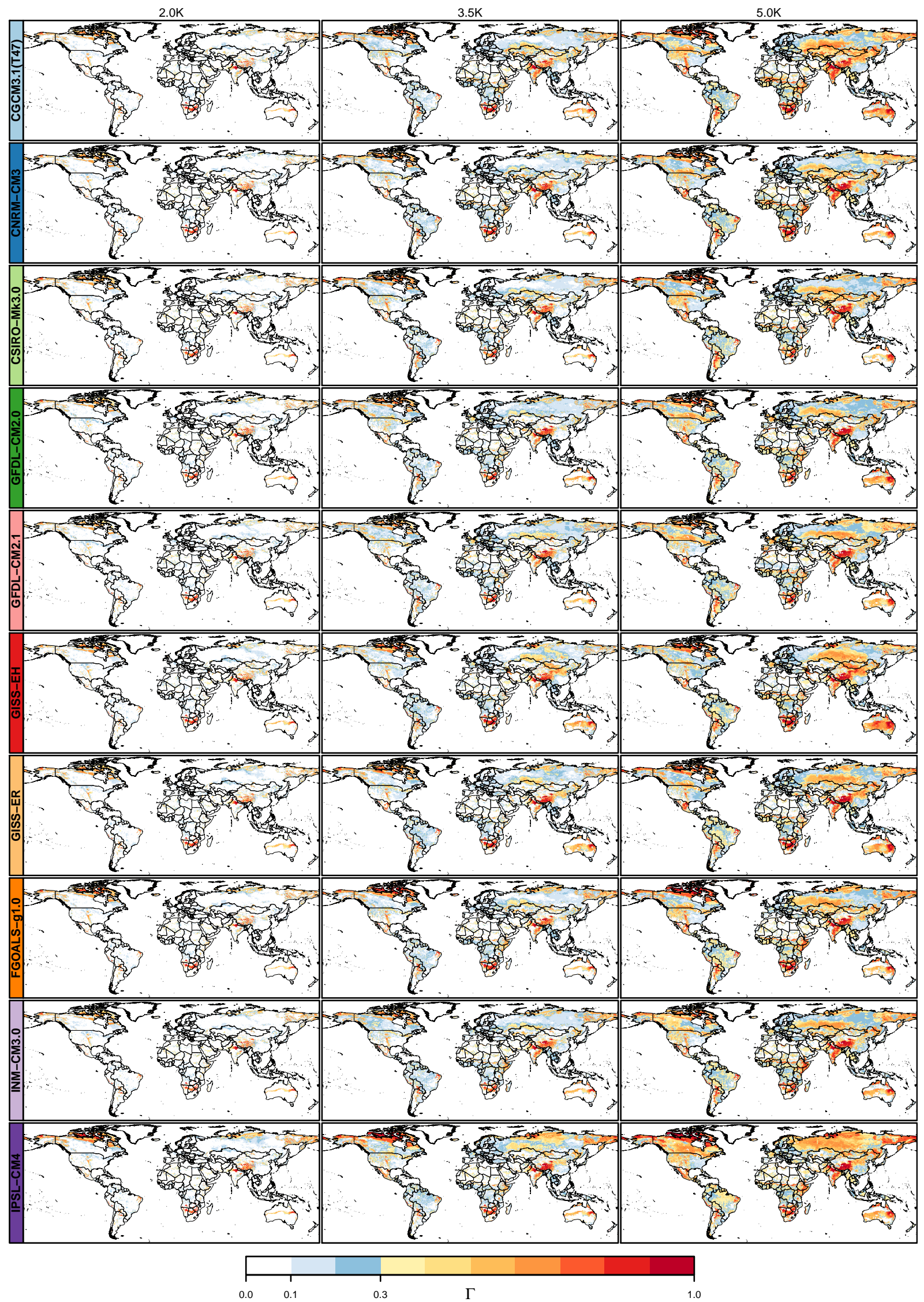

Fig. S8. Maps of $\Gamma$ values from individual simulation runs, grouped by AOGCM (rows) and warming level (columns). Colour coding of models corresponds to Fig. 5 in main text. 

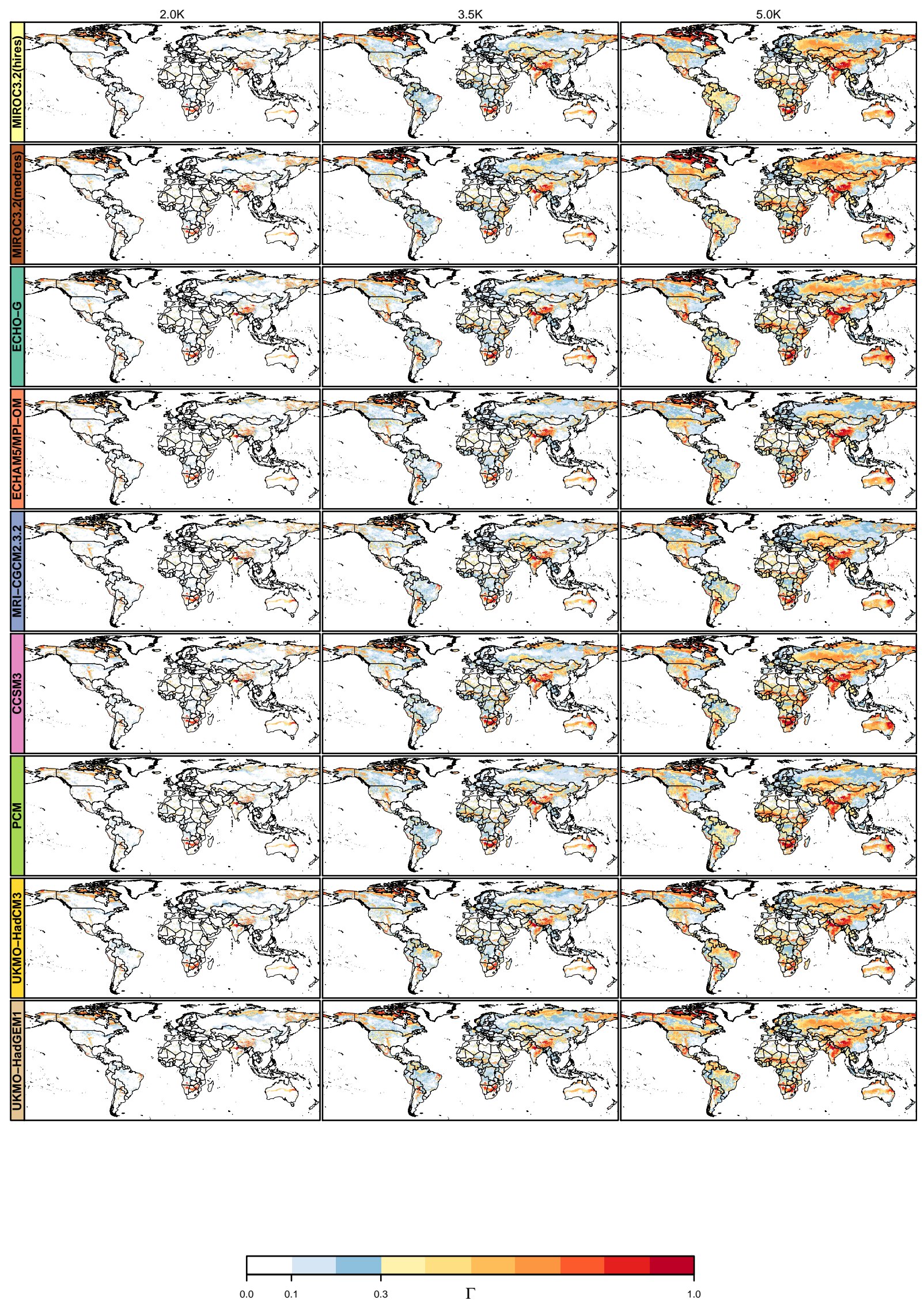

Fig. S8. Maps of $\Gamma$ values from individual simulation runs (continued). 


\section{References}

Beringer, T., Lucht, W., and Schaphoff, S.: Bioenergy production potential of global biomass plantations under environmental and agricultural constraints, GCB Bioenergy, 3, 299-312, doi:10.1111/j.1757-1707.2010.01088.x, 2011.

Bondeau, A., Smith, P. C., Zaehle, S., Schaphoff, S., Lucht, W., Cramer, W., Gerten, D., Lotze-Campen, H., Müller, C., Reichstein, M., and Smith, B.: Modelling the role of agriculture for the 20th century global terrestrial carbon balance, Global Change Biology, 13, 679-706, doi:10.1111/j.1365-2486.2006.01305.x, 2007.

Fader, M., Rost, S., Müller, C., Bondeau, A., and Gerten, D.: Virtual water content of temperate cereals and maize: Present and potential future patterns, J. Hydrol., 384, 218-231, doi:10.1016/j.jhydrol.2009.12.011, 2010.

Heinke, J., Ostberg, S., Schaphoff, S., Frieler, K., Müller, C., Gerten, D., Meinshausen, M., and Lucht, W.: A new climate dataset for systematic assessments of climate change impacts as a function of global warming, Geosci. Model Dev., in press.

Portmann, F. T., Siebert, S., and Döll, P.: MIRCA2000Global monthly irrigated and rainfed crop areas around the year 2000: A new high-resolution data set for agricultural and hydrological modeling, Global Biogeochem. Cycles, 24, doi:10.1029/2008GB003435, 2010.

Rudolf, B., Becker, A., Schneider, U., Meyer-Christoffer, A., and Ziese, M.: GPCC Status Report December 2010 (On the most recent gridded global data set issued in fall 2010 by the Global Precipitation Climatology Centre (GPCC)), Tech. Rep., DWD/GPCC, Offenbach/Main, Germany, http://gpcc.dwd. de, 2010.

Sankaran, M., Ratnam, J., and Hanan, N. P.: Tree-grass coexistence in savannas revisited - insights from an examination of assumptions and mechanisms invoked in existing models, Ecology Letters, 7, 480-490, doi:10.1111/j.1461-0248.2004.00596.x, 2004.

Sykes, M. T., Prentice, I. C., and Laarif, F.: Quantifying the impact of global climate change on potential natural vegetation, Climatic change, 41, 37-52, http://cat.inist.fr/?aModele= afficheN\&cpsidt=1846543, 1999. 